\title{
A RELAÇÃO ENTRE OS ESTUDANTES DOS ANOS FINAIS DO ENSINO FUNDAMENTAL E OS YOUTUBERS
}

\author{
Karine Matos Mota da Silva ${ }^{1 *}$, Teresa Claudina de Oliveira Cunha ${ }^{1} \&$ Shayane Ferreira \\ dos Santos ${ }^{1}$
}

\begin{abstract}
RESUMO
SILVA, K.M.M..; CUNHA, T.C.O.; SANTOS, S.F. A relação entre os estudantes dos anos finais do ensino fundamental e os youtubers. Perspectivas Online: Humanas \& Sociais Aplicadas, v.11, n.30, p.17 -37, 2021.
\end{abstract}

Segundo o "Relatório Digital in 2019", $95 \%$ dos participantes afirmaram que o Youtube é a rede social mais utilizada no Brasil. Devido ao grande número de acessos e à popularidade que a plataforma possui, justifica-se a presente pesquisa. Os produtores independentes de conteúdo são chamados Youtubes e esses profissionais acumulam números, tanto de inscritos em seus canais quanto em visualizações, tornando-se populares, conhecidos como influenciadores digitais, alcançando o sucesso nacional e/ou internacional. Esta pesquisa teve como objetivo principal analisar a influência dos Youtubers na formação dos estudantes dos anos finais do Ensino Fundamental. A população da pesquisa totalizou 194 estudantes, distribuídos entre a rede pública e privada de ensino do município de Campos dos Goytacazes, RJ e 2 Youtubers locais. Na metodologia optou-se pela pesquisa bibliográfica e de campos, de caráter qualitativo. Para a coleta de dados utilizou-se dos instrumentos: entrevista e questionário online da plataforma surveymonkey. Após a análise dos resultados obtidos, pode-se constatar que os estudantes gostam do Youtube; passam de uma a três horas por dia na plataforma; que a motivação para a busca e inscrição nos canais envolve os critérios de originalidade, autenticidade e inteligência e que os segmentos mais acessados são os de humor, música e games.

Palavras-chave: Influência; youtube; redes sociais. 


\title{
THE RELATIONSHIP BETWEEN STUDENTS IN THE FINAL YEARS OF FUNDAMENTAL EDUCATION AND YOUTUBERS
}

\begin{abstract}
According to the "Digital Report in 2019", 95\% of the participants stated that Youtube is the most used social network in Brazil. Due to the large number of accesses and the popularity that the platform has, this research is justified. Independent content producers are called Youtubes and these professionals accumulate numbers, both of subscribers in their channels and in views, becoming popular, known as digital influencers, achieving national and / or international success. This research had as main objective to analyze the influence of the Youtubers in the formation of the students of the final years of Elementary School. The research population totaled 194 students, distributed between the

public and private schools in the municipality of Campos dos Goytacazes, RJ and 2 local Youtubers. In the methodology, bibliographic and field research, of a qualitative character, was chosen. For data collection, the following instruments were used: interview and online questionnaire from the surveymonkey platform. After analyzing the results obtained, it can be seen that students like YouTube; spend one to three hours a day on the platform; that the motivation for searching and subscribing to channels involves the criteria of originality, authenticity and intelligence and that the most accessed segments are humor, music and games.
\end{abstract}

Keywords: Influence; youtube; social networks.

\footnotetext{
${ }^{1}$ Institutos Superiores de Ensino do CENSA - ISECENSA - Laboratório de Formação de Professores - LAFORP NUPED/ISECENSA - Rua Salvador Correa, 139, Centro, Campos dos Goytacazes, RJ, CEP: 28035-310, Brasil. (*)e-mail: karinemota24@gmail.com Data de recebimento: 23/01/2021. Aceito para publicação: 24/02/2021. Data da publicação: 14/04/2021.
} 


\section{INTRODUÇÃO}

Bauman (2007) afirma que os tempos são "líquidos" porque tudo muda rapidamente, nada é feito para durar para sempre, para ser "sólido". Em entrevista à revista ISTOÉ (2010), caracteriza a modernidade líquida como: "Líquidos mudam de forma muito rapidamente, sob a menor pressão. Na verdade, são incapazes de manter a mesma forma por muito tempo. No atual estágio "líquido" da modernidade, os líquidos são deliberadamente impedidos de se solidificarem".

Questionado sobre “O que está por trás desse culto às celebridades?” declara que não é apenas uma questão de aspirantes a celebridades e sim a necessidade de a sociedade de eleger pessoas para estar no centro das atenções.

Pessoas que, na ausência de autoridades confiáveis, líderes, guias, professores, se oferecem como exemplos. Diante do enfraquecimento das comunidades, essas pessoas fornecem "assuntos-chave" em torno dos quais as quase-comunidades, mesmo que apenas por um breve momento, se condensam - para desmoronar logo depois e se recondensar em torno de outras celebridades momentâneas. É por isso que a indústria de celebridades está garantida contra todas as depressões econômicas (BAUMAN, 2007, s/p).

Dias (2005) afirma que a sociedade contemporânea, ao romper com as práticas e paradigmas tradicionais, destaca a cultura das potencialidades particulares, proporcionando ao sujeito social uma identidade "móvel", mutável. Dentro dessa perspectiva, o autor (2005, p. 87) pondera que “o 'eu' torna-se, cada vez mais, um projeto reflexivo, pois aonde não existe mais a referência da tradição, descortina-se, para o indivíduo, um mundo de diversidade, de possibilidades abertas, de escolhas".

Gerações vão surgindo com particularidades, definidas por uma contagem de tempo linear, entretanto, não apenas essa dimensão deve ser observada, vale ressaltar que existe uma coexistência entre as gerações. Segundo Maurer (2013, p. 24) o conceito de geração vai além de datas de nascimento, mas também compreende os acontecimentos e experiências vividas. Desta forma, o autor defende que "o conceito de geração comportaria uma dimensão biológica (nascimento e morte) e uma social (o processo de vivências e experiências)".

\subsection{Geração $X$}

A geração denominada "X" envolve as pessoas nascidas entre 1961 e 1977, numa sociedade caracterizada por profundas e drásticas transformações de diversas ordens. Acontecimentos históricos e sociais interferiram na vivência das pessoas e as influenciam diretamente. Maurer (2013, p 31) assegura que "no Brasil, entre os anos de 1961 e 1981, aconteceram muitos fatos que influenciaram a formação da identidade dessa geração". O autor cita, como exemplo de enfrentamento, a arte, que surge como um instrumento "silencioso" de protesto contra o Estado, à época caracterizado por um regime militar, fomentando a participação de grandes artistas e personalidades da música, no teatro, na literatura, na educação e na política.

No intervalo de tempo que caracteriza essa geração, a humanidade foi protagonista de mudanças sociais profundas, através de fatos como guerras, revoluções e novas tecnologias. Muitas das ferramentas de comunicação que se usam hoje foram criadas e consumidas pelos X's. Essas mudanças sociais influenciaram o amadurecimento dessa geração, que veio então preparando um ambiente multifacetado para seus filhos, um novo modo de viver e perceber o mundo (MAURER, 2013, p. 31). 
Percebe-se que a evolução das tecnologias, como televisão e o rádio, marcou a Geração X e, apesar dos desafios enfrentados, ocorreram movimentos de resistência, criações e trasnformações de ordens diversas no Brasil. O próximo tópico descreve a geração Y, suas características no contexto social e histórico.

\subsection{Geração $Y$}

Segundo Comazzetto et al. (2016) a Geração Y abarca as pessoas nascidas entre 1978 e 1992, com personalidade focada no imediatismo e na forte relação com as tecnologias, pois foi a primeira geração a ter um contato mais direto em seu cotidiano.

Prensky (2001, p. 1) destaca um fenômeno que aconteceu nas últimas décadas do século XX que desencadeou mudanças e provocou características na geração que o vivenciou. Argumenta que pode até ser compreendida como "um evento no qual as coisas são tão mudadas que não há volta [...]". O autor define os nascidos nessa época de nativos digitais, que recebem e processam informações muito rapidamente, assim como realizam múltiplas tarefas. Indivíduos que "preferem acesso aleatório (como hipertexto). Eles trabalham melhor quando ligados a uma rede de contatos. Eles têm sucesso com gratificações instantâneas e recompensas frequentes" (PRENSKY, 2001, p. 2).

Dentro desse contexto, Prensky (2001) denomina os (nativos) das gerações anteriores como Imigrantes Digitais. E como todo imigrante, pode até aprender o novo idioma, alguns mais que outros, cada um no seu tempo.

Percebe-se que, na Geração Y, dos nativos Digitais, existe uma multiplicidade de gerações que dividem os mesmos ambientes: são os de nativos e imigrantes digitais e até mesmo de nativos que ajudam os imigrantes a reduzirem as dificuldades diante do novo.

Coelho (2012) afirma que os Y's convivem bem no cenário da internet, rodeados de ferramentas que possuem comunicação instantâneas. No entanto, ressalta que essa velocidade na informação influenciou em toda a geração, gerando impaciência, e seus membros a solução para agora. A Geração $\mathrm{Y}$ está inserida e se desenvolve em uma sociedade em que "a comunicação digital tem um papel fundamental tanto na sua formação quanto na compreensão da realidade, pois é a partir da expansão das novas tecnologias que essa geração se expressa e interage seja por meio de sons, imagens e textos escritos e verbais" (COELHO, 2012, p. 89). $\mathrm{O}$ autor finaliza dizendo que o importante, o que realmente interessa a essa geração são recompensas e oportunidades a curto prazo.

Segundo Engelmann (2009 apud MAURER, 2013, p. 33) a geração Y representa os "indivíduos que têm uma íntima relação com as tecnologias, pois amadureciam no período em que as tecnologias, como a internet, o computador e o telefone celular, ganhavam o mercado de consumo".

Um facilitador da Geração Y para compreender e saber usar a tecnologia foi o acesso à televisão desde a primeira infância. No próximo tópico, apresenta-se a geração $Z$, sua descrição e a contextualização social e histórica.

\subsection{GERAÇÃO Z}

A partir dos anos 2000 surge a Geração Z, com um aprofundamento das características de seus pais (Geração Y), apresentando comportamentos mentais e sociais modificados com o advento da tecnologia, o que possibilitou a criação de novos modos de pensar, decidir e 
avaliar.A relação dessa geração com o entorno social é na velocidade de mensagens de WhatsApp. Nasceram em meio à tecnologia e gostam de utilizá-la. Cortelazzo (2018, p. 60) destaca que:

A sensibilidade audiovisual é bem mais desenvolvida. Gostam de liberdade e de coisas com sua marca pessoal (é a personalização). São multitarefas e gostam de trabalhar em grupo, cooperativamente e colaborativamente. Se envolvem em muitos projetos ao mesmo tempo e abusam das interfaces com que se conectam, entre digital e o analógico, a distância e o físico.

A nomenclatura, Geração Z, vem do comportamento de Zapear, ou seja, mudar de canal na televisão, com certa velocidade, não se atentando a nenhum deles. Dando ênfase apenas à internet, sobretudo às redes sociais. Levenfus (2002 apud FAGUNDES, 2011, p. 40) afirma que "essa geração não se tranca no quarto para se isolar do mundo, mas sim para se plugar nele, tendo acesso a informações jamais obtidas por jovens de eras passadas, de dentro do quarto abrem $\mathrm{N}$ janelas para o mundo".

Nessa perceptiva, a Geração Z está cada vez mais ligados não apenas com o consumo de conteúdos que estão disponíveis na internet, mas também na criação da informação online, possibilitada pelo molde que a internet possui, sendo uma rede de colaboração.

Segundo Cortelazzo (2018), a Geração Z é também denominada de Geração Digital, na medida em que esses nativos se comunicam com seus amigos por meio de aplicativos e redes sociais, como WhatsApp, Twitter, Skype, Instagram e Facebook, mesmo não estando tão distante fisicamente deles. Valorizam números de seguidores, curtidas e compartilhamentos. Possuem inúmeras redes sociais e canal no Youtube, porém seu tempo de foco é restrito e sua distração fácil.

Maurer (2013, p.36) ainda destaca que "outra característica importante e que rotula bem essa geração é o mundo sem fronteiras. Para eles o mundo é pequeno e geograficamente tudo é perto, reflexo claro do mundo on-line". Necessária, portanto, uma atenção especial à grande quantidade de informação que os jovens dessa geração recebem, pois o desenvolvimento de habilidades para analisar e criticar o que recebem antes de acreditarem ingenuamente em tudo é essencial.

Fagundes (2011, p. 43) chama a atenção para o olhar sobre essa geração, destacando que, como todas as outras, possui pontos positivos e negativos. Afirma ainda que "o ideal seria que esta geração não fosse superestimada ou subestimada, e sim encarada como uma geração que, assim como as outras, possui suas qualidades e também suas carências". Para o autor:

A Geração $Z$ possui uma habilidade natural para utilizar da tecnologia com facilidade que chega a deixar os membros das gerações anteriores perplexos. No entanto, suas carências de habilidades para encontrar e utilizar adequadamente a informação na internet, seu 'habitat', visando seu aprendizado também surpreendem, contudo negativamente (FAGUNDES, 2011, p. 45).

A Base Nacional Comum Curricular (BRASIL, 2018, p. 8) diz que as aprendizagens essenciais são definidas para garantir aos estudantes o desenvolvimento de dez competências gerais para a Educação Básica. Apresenta na Competência 5 (denominada Cultura Digital), o fundamento de que se deve assegurar aos estudantes:

Compreender, utilizar e criar tecnologias digitais de informação e comunicação de forma crítica, significativa, reflexiva e ética nas diversas práticas sociais (incluindo as escolares) para se comunicar, acessar e disseminar informações, produzir 
conhecimentos, resolver problemas e exercer protagonismo e autoria na vida pessoal e coletiva (BRASIL, 2018, p. 10).

O documento admite, portanto, o papel primordial que a tecnologia apresenta na geração atual e estabelece que o uso deve ser adequado para que então haja um bom resultado. Essa geração não apenas absorve o que chega; esses jovens produzem, criam, opinam e compartilham ideias. Sendo assim, eles também podem ser Youtubers que influenciam outras crianças da mesma idade.

As redes sociais por meio das interações vêm modificando diversas áreas da atividade humana, a saber: comércio, indústria, economia, artes, cultura e educação, desde os mais remotos tempos da humanidade. Geralmente, uma RSI é usada para conhecer pessoas, disponibilizar fotos, vídeos, comentários, comercializar produto. Porém, também podem representar um importante recurso de apoio às atividades educacionais (BARCELOS, 2012, p. 5)

De acordo com Cortellazo (2018) os jovens da geração Z participam de atividades que estejam diretamente relacionadas ao verbo criar, pois isto possibilita que imprimam sua marca pessoal e compartilhem desde o início ao final do processo as informações, para que depois possaM também ser consumidores delas. Somente dessa maneira sentem-se participantes do processo, motivados a fazer e aprender.

\subsection{Youtube: publicar, curtir e compartilhar}

O YouTube foi fundado em 2005 de forma não muito pretensiosa por ex-funcionários de um site de comércio online, Chad Hurley, Steve Chen e Jawed Karim. Segundo Burgess (2009, p. 17), "a inovação original era de ordem tecnológica (mas não exclusiva): o YouTube era um entre os vários serviços concorrentes que tentavam eliminar as barreiras técnicas para maior compartilhamento de vídeos na internet".

O site possuía uma interface simples e intuitiva, possibilitando ao usuário assistir e publicar vídeos facilmente, dispensando altos níveis de conhecimento de programação, além de não limitar o número de publicações que o mesmo usuário poderia enviar. Em outubro de 2006, o Google comprou o YouTube por 1,65 bilhão de dólares e um pouco mais de um ano após a compra, em novembro de 2007 , ele já havia se tornado o site de entretenimento mais popular do Reino Unido. Burgess (2009, p. 37) cita que

O YouTube representa claramente uma ruptura com os modelos de negócios da mídia existentes e está surgindo como um novo ambiente do poder midiático. Ele tem recebido muita atenção da imprensa e agora faz parte, mesmo que aceito de maneira relutante, do cenário da mídia de massa: mas também é utilizado com regularidade como veículo para o ensaio de debates públicos sobre novas mídias e internet enquanto forças de desestabilização nos negócios e na sociedade, particularmente em relação aos jovens.

O site possui restrições à produção de conteúdo, sendo elas relacionadas às limitações legais referentes e às diretrizes de comunidade regidas pela própria plataforma que salva os direitos autorais. Bernardazzi e Costa (2017, p. 3-4) afirmam que:

Algumas das diretrizes envolvem restrições da publicação de conteúdo sexual,
violento, de incitação ao ódio, prejudicial, perigoso, ameaças. Vídeos que sejam
identificados com conteúdo relacionado a essas temáticas podem ser removidos pela
empresa ou sofrer restrição de idade no momento de visualização. A própria
comunidade do YouTube pode denunciar conteúdo que infrinja as diretrizes do

Persp. Online: hum \& sociais aplicada., Campos dos Goytacazes, 30 (11)17-37- 2021 
usuário. Uma forma de fazer com quem os próprios produtores e consumidores do conteúdo possam intervir na convivência desse microuniverso.

Sendo assim, o próprio usuário, produtor ou consumidor, pode participar da manutenção do conteúdo da plataforma, denunciando o que achar impróprio. Essa atitude possibilitará o bloqueio ou até mesmo a exclusão desse conteúdo.

De acordo com Costa (2019) o crescimento e popularidade do site tem sido gigante. Em 2019, no Brasil, tornou-se a rede social mais utilizada e a segunda maior no mundo. O "Relatório Digital in 2019", realizado pela "We Are Social", juntamente com a Hootsuite, demonstra que $66 \%$ da população brasileira usa redes sociais, o que representa aproximadamente 140 milhões de usuários. De acordo com os dados da pesquisa, $95 \%$ dos participantes afirmaram que o site de vídeos é a plataforma mais utilizada.

\subsubsection{Dos Youtubers}

Os produtores independentes de conteúdo da plataforma são chamados Youtubers.Para se tornar um, basta criar uma conta no Youtube e alimentar esse canal com vídeos. Esses profissionais acumulam números, tanto de inscritos em seus canais quanto em visualizações, tornando-se populares e conhecidos como influenciadores digitais, alcançando o sucesso nacional e/ou internacional. Sammur, Silva e Cortez (2018) destacam que os estudos realizados pelos mesmos apresentaram que sobre "as práticas profissionais no Youtube nota-se uma sobreposição entre o trabalho do Youtuber e o indivíduo habilitado em comunicação social". Nessa perspectiva, os autores ainda indagam: Seria Youtuber realmente uma profissão ou unicamente um "vácuo" gerado pela
ausência de comunicadores profissionais que, desconhecendo as oportunidades e
forma de inserção no digital, tornam este espaço acessível e competitivo para
indivíduos que produzem conteúdo de maneira assistemática baseando-se em
"ensaio e erro"? Independentemente da possível resposta a esse questionamento é
importante que os futuros comunicadores possuam matérias relacionadas às mídias
digitais no currículo, incluindo o Youtube, que vêm se demonstrando uma
plataforma de mídia crescente (SAMMUR, SILVA E CORTEZ, 2018, p.
6).

Hélio Teixeira (2015) afirma que a influência social acontece quando o comportamento de um indivíduo é modificado na presença de outro e que esse outro não precisa estar presente fisicamente, mas pode ser imaginado.

Kiuchi, Silva e Gomes (2018, p.2) ressaltam que "com o advento da internet, a presença passa de imaginária a virtual. A globalização da internet possibilitou a criação de formatos que nenhum outro meio de comunicação produzia, isto é, a produção de conteúdos caseiros, como forma de expressão livre de opiniões". Os autores acrescentam ainda que no cenário do entretenimento brasileiro acontece agora, na geração Z, o auge da carreira desses influenciadores digitais. Os donos dos maiores canais do país são, geralmente, jovens e adultos jovens de até 35 anos, que compartilham experiências de vida de forma bem humorada. Diversas linguagens estão presentes em seus vídeos, com apelos visuais, sonoros além de Marketing direto ou indireto.

Referente ao crescimento da plataforma e a possibilidade de ascensão e popularidade dos produtores de conteúdo, ocorre então um processo inverso ao que é observado há anos, uma vez que as celebridades migram da internet para os meios de comunicação tradicionais. Isso ocorre quando Youtubers são convidados para programas, ou mesmo são os apresentadores. A fama criada a partir da plataforma possibilitou também que muitos fossem 
para o cinema e vendessem milhares de livros. De acordo com Henry Jenkins (2013), existem três etapas diferentes para que essa participação ocorra: produção, seleção e distribuição. A plataforma YouTube une todas essas etapas e essa característica explica o sucesso no mercado.

Dentro desse contexto, a presente pesquisa tem como objetivo principal analisar a influência dos Youtubers na formação dos estudantes dos anos finais do Ensino Fundamental. Para Moscardi et al. (2017, p. 304) compreende que "os adolescentes têm sido o alvo mais frequente das influências exercidas pela mídia na internet por se encontrarem em pleno desenvolvimento de sua personalidade, o que afeta suas capacidades reflexivas e seu senso crítico".

Busca-se apresentar e discutir sobre os produtores de conteúdo do YouTube e as diversas linguagens presentes nos vídeos, na próxima sessão esses temas serão abordados.

\section{METODOLOGIA}

O presente trabalho tem como objetivo principal analisar a influência dos Youtubers na formação dos estudantes dos anos finais do Ensino Fundamental. O lócus espacial foi o município de Campos dos Goytacazes/RJ.

Para tanto, adotou-se quanto à abordagem do problema, uma metodologia de caráter qualitativo, pois "considera que há uma relação dinâmica, particular, contextual e temporal entre o pesquisador e o objeto de estudo. Por isso, carece de uma interpretação dos fenômenos à luz do contexto, do tempo, dos fatos" (MICHEL, 2009, p. 36-37). Nesta pesquisa, o ambiente natural é a principal fonte para obtenção dos dados e o pesquisador deverá ter a capacidade de interpretar essa realidade, com isenção e lógica, buscando respostas para o problema levantado.

O estudo, quanto aos objetivos apresenta-se como sendo de natureza descritiva, pois tem como fundamento principal "a descrição das características de determinada população ou fenômeno ou, então, o estabelecimento de relações entre as variáveis” (GIL, 1993, p.46).

Quanto aos procedimentos, utilizou-se da pesquisa bibliográfica e de campo. Michel (2009) considera que a pesquisa bibliográfica implica leituras intensas sobre o tema, embora este não seja o propósito final da pesquisa. Além disso, complementa dizendo que é uma etapa auxiliar na definição de objetivos e levantamento de informações sobre o objeto de estudo.

A presente pesquisa teve como população 194 estudantes matriculados nos anos finais do Ensino Fundamental, sendo que $71 \%(\mathrm{~N}=138)$ pertencem a rede privada de ensino e $28 \%$ $(\mathrm{N}=55)$ a rede pública do município de Campos dos Goytacazes, RJ. Os instrumentos utilizados para a coleta de dados foram questionários semiestruturados, contendo perguntas abertas e fechadas e entrevista a 02 (dois) Youtubers em níveis local. Os dados coletados foram interpretados e analisados à luz dos referenciais teóricos utilizados ao longo da revisão de literatura.

\section{RESULTADOS E DISCUSSÃO}

Dando início a pesquisa, buscou-se identificar se os estudantes respondentes utilizam redes sociais, $84 \%(\mathrm{~N}=162)$ afirmaram que sim, $2 \%(\mathrm{~N}=3)$ disseram que não utilizam e $15 \%$ $(\mathrm{N}=29)$ não responderam à pergunta. 
Segundo o IBGE, em 2015, 10 mil crianças de 10 a 14 anos utilizaram Internet, Maffesoli (1998 apud SOUZA; CARDOSO, 2011) chama a atenção sobre as redes serem compostas por pessoas, utilizando metáforas. $\mathrm{O}$ autor afirma que:

[...] as coisas, as pessoas, as representações se propagam por um mecanismo de
proximidade. Assim, é por contaminações sucessivas que se cria aquilo que é
chamado de realidade social. Através de uma sequência de cruzamentos e de
entrecruzamentos múltiplos se constitui em uma rede das redes. Os diversos
elementos limitam-se entre si, formando, assim, uma estrutura complexa. Entretanto,
a oportunidade, o acaso, o presente representam nela uma parte não negligenciável.
E isso dá ao nosso tempo o aspecto incerto e estocástico que conhecemos bem. O
que não impede, por pouco que se saiba ver, que nela esteja agindo uma
organicidade sólida que sirva de base às novas formas de [...] socialidade.
(MAFFESOLI, 1998 apud SOUSA; CARDOSO, 2011, p. 66-67).

Questionados sobre a rede social mais utilizada, a pesquisa enfatiza, principalmente, o uso de três redes sociais, Instagram $(\mathrm{N}=114)$, Youtube $(\mathrm{N}=70)$ e WhatsApp $(\mathrm{N}=61)$. A Agência MOLL (2020), focada no marketing digital e na utilização das redes, destaca que, no Brasil, em 2020, as principais redes sociais foram, em primeiro lugar, o Facebook seguido respectivamente pelo Youtube, WhatsApp e Instagram. A pequisa ressaltou a facilidade de empreendedores encontrarem seus públicos alvos nessas plataformas, visto que diversas pessoas com gostos distintos as frequentam.

\subsection{Do acesso e da utilização do Youtube}

Considerando a temática principal da pesquisa, o uso da plataforma de vídeos Youtube, os participantes foram questionados quanto a sua relação com esta ferramenta. Desses, $71 \%$ $(\mathrm{N}=138)$ responderam gostar muito, $15 \%(\mathrm{~N}=29)$ não responderam, $10 \%(\mathrm{~N}=19)$ responderam tanto faz, o que pode mostrar a indiferença quanto ao uso do Youtube, $3 \%(\mathrm{~N}=6)$ responderam gostar pouco e $1 \%(\mathrm{~N}=2)$ não utiliza.

Estudo realizado, em 2018, pelo Pew Research Center, chamado The Verge revela o Youtube como a plataforma social preferida dos adolescentes e jovens. Segundo o "Relatório Digital in 2019" no Brasil são mais de 140 milhões de usuários de redes sociais e entre eles 95\% afirmam que o Youtube é o mais utilizado.

De pessoas anônimas, youturbers tornam-se celebridades na internet. Whindersson Nunes, por exemplo, dono do segundo maior canal do Youtube no Brasil (2020), em entrevista ao programa de Danilo Gentili afirmou, "eu dormi e acordei famoso". A afirmativa de Whindersson Nunes justifica-se, pois já publicava vídeos na plataforma e não obtinha um resultado positivo. Afirma ter se surpreendido após a publicação de um vídeo (paródia "Alô Vó") e perceber que se tornou viral. Esses grandiosos números têm provocado uma mudança na vida dos Youtubers.

Com a popularização da internet, qualquer indivíduo tem a possibilidade de ser um produtor de conteúdo, e aqueles que, por determinado motivo, adquirem vários seguidores na rede tornam-se influenciadores digitais. A plataforma de postagem de vídeos Youtube abriu portas para que muitas pessoas expressassem ideias criativas, habilidades humorísticas; compartilhassem experiências de vida, ensinassem as mais diversas receitas, entretivessem os internautas com gameplays de terror e fizessem as demais rir com vídeos de react (KIUCHI; SILVA; GOMES, 2018, p. 5).

A velocidade foi um pouco menor para Babi, jogadora de Free Fire e integrante do canal "Loud",-foi bastante significativa. Em um vídeo no referido canal, em que foi apresentada como a primeira menina a participar da equipe, Babi disse "minha vida mudou 
totalmente. De Direito para o ramo dos jogos. Eu tinha 5 mil seguidores e hoje estou com mais de 1.800.000. É insano!”

No Youtube quando é acessada a aba "Em alta" (Figura 1), encontram-se os vídeos que possuem grande número de interações e isso engloba as diferentes chamadas para ação, como visualizações, curtidas, comentários e compartilhamento, ranking que varia diariamente.

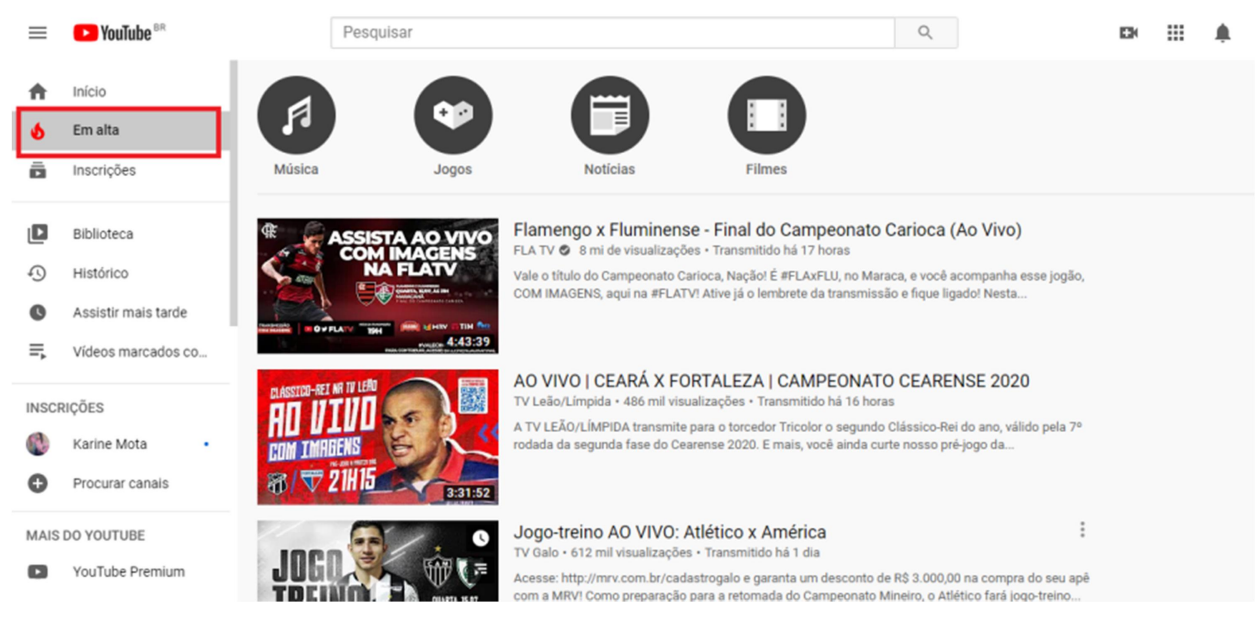

Figura 1: Imagem demonstrativa da Aba "Em alta" do youtube

Fonte: https://www.youtube.com/feed/trending

Dando prosseguimento à pesquisa, perguntou-se sobre quais categorias eram mais as preferidas assistidas pelos estudantes em primeiro lugar, a Tabela 1 indica o Humor $(\mathrm{N}=87)$, em segundo Música $(\mathrm{N}=76)$ e em terceiro Games $(\mathrm{N}=59)$.

Tabela 1: Das Categorias do Youtube. Fonte: Elaboração própria. Pesquisa de campo.

\begin{tabular}{l|l}
\hline Opções & $\mathbf{N}^{\mathbf{0}}$ \\
\hline Humor & 87 \\
\hline Música & 76 \\
\hline Beleza & 52 \\
\hline Games & 59 \\
\hline Estudos & 27 \\
\hline Esportes & 24 \\
\hline Viagem & 23 \\
\hline Outro & 29 \\
\hline Não responderam & 30 \\
\hline
\end{tabular}

Sousa $(2017$, p. 2) em sua pequisa sobre a influência dos Youtubers na personalidade do adolescente, apresenta um resultado semelhante à da presente pesquisa, quando afirma que:

As temáticas preferidas pelos adolescentes foram: humor, imitações, seriados, jogos online, beleza, trolagens, orientação sexual, questões sociais, políticas, estudos, futebol e músicas. Os participantes afirmam ficar em média 5 horas por dia conectados assistindo vídeos e seguindo os Youtubers nas redes sociais para saberem o assunto do próximo vídeo, bem como, acompanhar a vida dos mesmos. 
Em seguida, buscou-se saber dos estudantes a definição de Youtuber. Como a pergunta foi aberta, foram obtidas diversas respostas, mas algumas foram mais comuns. A Tabela 2, apresenta fragmentos das falas mais relevantes:

Tabela 2: O que são Youtuber's?. Fonte: Elaboração própria / Pesquisa de campo.

"Youtuber são pessoas que influenciam outras pessoas, seja elas influências boas ou ruins. Elas oferecem conteúdos de acordo com o gosto de público e de seus seguidores."

"Alguém que tem o YouTube como fonte de renda."

"Criador de conteúdo digital, assim como os canais de televisão."

"Uma pessoa que usa pelo meio digital, formas de se comunicar com pessoas que se identificam com ela, assim trazendo um bom conteúdo, que essas pessoas gostem."

"Uma pessoa que trabalha com a ferramenta YouTube"

"Uma pessoa que grava vídeos para ganhar inscritos é likes com o objetivo de ir ganhando placas que o YouTube dá a cada milhão de inscritos"

"Uma pessoa que grava vídeo para YouTube"

"Uma pessoa que busca entreter um público com um determinado assunto."

"UMA CELIBRIDADE"

"Um YouTuber, também conhecido como personalidade do YouTube, celebridade do YouTube ou criador de conteúdo do YouTube, é um tipo de celebridade e cinegrafista da Internet que ganhou popularidade no site de compartilhamento de vídeos YouTube."

"Um YouTube tem que ser educado, tem que ter bastante paciência e tem que produzir conteúdo."

"Um influencer digital, que dá informações sobre sua vida, o que faz, o que gosta de fazer."

"Pessoas que gravam vídeos para o YouTube."

"É uma pessoa que grava vídeos que desperta a vontade de assistir certa coisa."

"É uma pessoa que faz vídeo para o YouTube, para ganhar dim dim."

Os Youtubers são denominados “Influenciadores Digitais". Sousa et al. (2017, p. 2) compreendem que:

Diante das transformações ocorridas na sociedade contemporânea, com o advento da internet vivemos em uma sociedade conectada com as mídias sociais e com isso um cidadão comum pode se tornar mais conhecido e influenciar o comportamento de jovens. Isso pode ser possível com uma câmera na mão, uma ideia na cabeça e uma 
plataforma como, por exemplo, o You Tube, então surge o fenômeno conhecido como youtuber. Essas pessoas são fenômenos midiáticos, pois ao gravar vídeos sobre assuntos variados para entreter seu público, conseguem a adesão de milhares de pessoas e acabam lucrando/ganhando em média US\$ 1 a cada mil visualizações por vídeos.

Questionados sobre quantos canais no Youtube estão inscritos. 69\% ( $\mathrm{N}=133)$ dos estudantes afirmaram que possuem inscrições em no mínimo 3 canais, o que demonstra uma ativa participação $n a$ plataforma.

Para responder ao questionamento de como o Youtube é capaz de despertar o interesse de tantas pessoas, Coelho e Campos (2019, s/p) afirmam que:

Se você se perguntar ao que assistiu ontem à noite no YouTube, há grandes chances de ter sido alguma coisa para aprender. Seja para descobrir como tirar uma mancha de roupa, resolver um cubo mágico, passar no ENEM, estudar inglês, aprender programação, yoga, meditação ou a história da Guerra Fria, o YouTube é o lugar onde os brasileiros buscam conhecimento. E essa lógica do aprendizado também pode ser notada em temas como Esporte, Moda e Beleza, Culinária e Entretenimento.

A Figura 2 apresenta o resultado de uma pesquisa sobre acesso a vídeos diversos disponíveis no Youtube e com o destaque para o fato de $79 \%$ dos brasileiros afirmarem o quanto aprendem algo diferente.
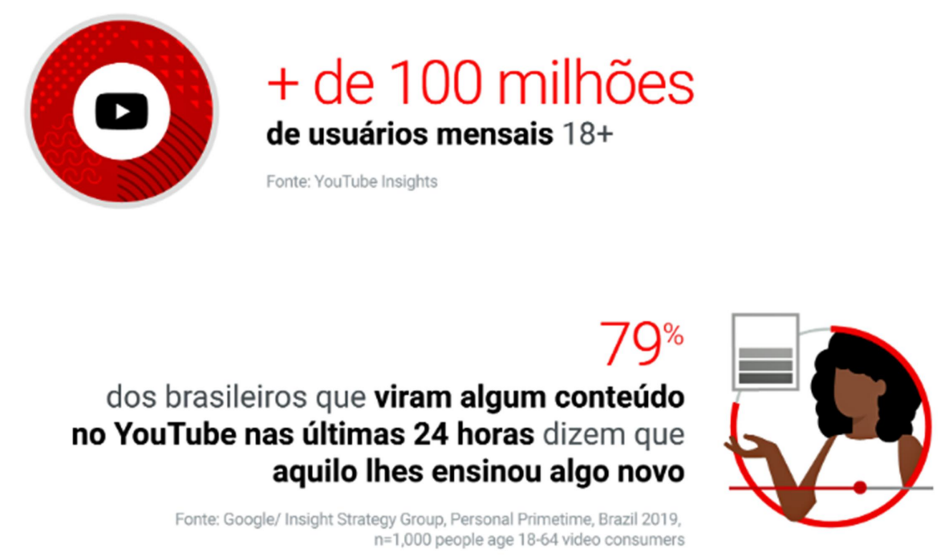

Figura 2: YouTube: único para todo mundo

Fonte: Disponível em: https://www.thinkwithgoogle.com/intl/pt-br/advertisingchannels/v\%C3\%ADdeo/youtube-unico-para-todo-mundo/

Questionados se já indicaram para seus amigos os canais que participam, 55\% $(\mathrm{N}=106)$ responderam que sim, enquanto $29 \%(\mathrm{~N}=57)$ que não, e nessa questão $16 \%(\mathrm{~N}=31)$ não responderam.

Marco Túlio, criador e dublador de histórias de Minecraft em seu canal do Youtuber "Authentic Games", que possui a marca de mais de 19 milhões de inscritos, afirmou em entrevista ao Pedro Bial que:

"Hoje os próprios inscritos (os maninhos e as maninhas como eu costumo falar) vão me indicando para outros". 


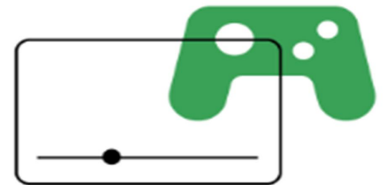

O interesse de busca no YouTube por "gaming" quase dobrou desde o ano passado.

Fonte: Google Trends, Global, 12 de maio de 2019-9 de maio de 2020.

Figura 3: Buscas no YouTube por games

Fonte:https://www.thinkwithgoogle.com/intl/pt-br/tendencias-de-consumo/a-industria-dosgames-respondeu-bem-a-pandemia-veja-3-ensinamentos-que-podem-impactar-o-seumarketing/

Dentro desse contexto Marianna Nash (2020, s/p) compreende que a plataforma Youtube possibilita ser social, mesmo a distância. Indica, por exemplo, que:

\begin{abstract}
Os jogos conectam milhões de pessoas em todo o mundo, todos os dias. Seja com creators compartilhando dicas no YouTube, seja com ambientes criativos no gameplay, todos estão atrás de experiências virtuais que os ajudem a cultivar relacionamentos, tanto os já existentes quanto os novos.
\end{abstract}

Nash (2020, s/p) afirma ainda que "as visualizações de games em streaming também estão crescendo. Além de jogarem juntas, as pessoas estão formando comunidades online altamente engajadas, em plataformas que as permitem assistir e comentar os games em tempo real".

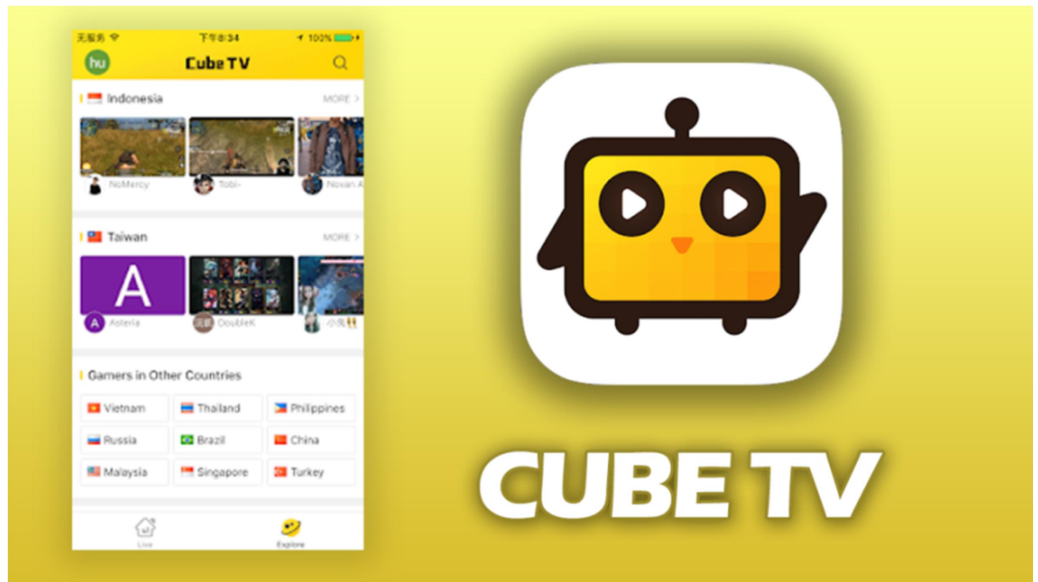

Figura 4: O que são plataformas de streaming de games?

Fonte: Disponível em: https://influu.me/blog/o-que-sao-plataformas-streaming-games/.

Acesso em: 14 jul. 2020.

Em seguida, buscou-se identificar o Youtuber favorito dos estudantes. Os que se destacaram nas respostas, foram verdadeiros milionários da plataforma, a mais citada foi Camila Loures que possui em seu canal do YouTube 11,9 milhões de inscritos. Em segundo lugar, foi o Youtuber Felipe Neto, que possui a marca de 38,5 milhões de inscritos. Em terceiro lugar, o Lucas Rangel que conta mais de 9,36 milhões inscritos e, o quarto lugar, a Luiza Parente com 3.6 milhões de inscritos.

Felipe Neto em seu vídeo intitulado como "Draw mylife", contou sobre sua vida pessoal e destacou sua relação com o Youtube como sucesso profissional, pois faz aquilo que ama: 
"O Youtube me trouxe a felicidade que eu sempre procurei, a alegria de viver fazendo o que eu mais amava, criar conteúdo, de alegrar as pessoas, divertir, atuar..."

O que esses Youtubers têm em comum, é que todos são relativamente jovens, entre 18 e 30 anos. Possuem um público infanto-juvenil e são conhecidos pelos vídeos irreverentes, contendo desafios, curiosidades e trolagens, tudo com humor.

Sobre as horas passadas na plataforma $34 \%(\mathrm{~N}=56)$ dos estudantes responderam que passam de uma a três horas por dia, enquanto $31 \%(\mathrm{~N}=52)$ afirmaram que ficam uma hora e $11 \%(\mathrm{~N}=18)$ gastam de três a cinco horas na programação de seus canais favoritos.

Para Sousa (2017), os participantes afirmaram ficar em média 5 horas por dia conectados, assistindo vídeos e seguindo os Youtubers nas redes sociais para saberem o assunto do próximo vídeo, bem como, acompanhar a vida dos mesmos.

Ainda sobre acesso, identificação e envolvimento com canais, Coelho e Campos (2019, s/p) ressaltam que:

Se pudéssemos desenhar o YouTube como um ecossistema, ele se apoiaria em três pilares: criadores, conteúdo e audiência. Os grandes motores para garantir esse ecossistema vivo são a identificação e a paixão. Ou seja, quando as pessoas assistem a vídeos online, elas querem se reconhecer, encontrar grupos com que se identificam e assistir a toda a pluralidade do mundo.

O ponto primordial da presente pesquisa encontra-se na Tabela 3, que reúne conjunto de questões diretamente relacionadas ao objetivo principal da pesquisa: influência dos Youtubers na formação do indivíduo 
Tabela 3: Percepção dos estudantes sobre a influência do Youtuber no cotidiano.Fonte: Elaboração própria / Pesquisa de campo.

\begin{tabular}{|c|c|c|c|c|c|c|c|}
\hline Opções & \multicolumn{2}{|c|}{ Sim } & \multicolumn{2}{|c|}{ Não } & \multicolumn{2}{|c|}{ Às vezes } & Total \\
\hline Você já teve ou tem vontade de se tornar um Youtuber? & $51 \%$ & & $20 \%$ & 33 & $28 \%$ & 46 & 162 \\
\hline Você utiliza gírias ou expressões de Youtbers? & $49 \%$ & 80 & $15 \%$ & 24 & $36 \%$ & 58 & 162 \\
\hline $\begin{array}{l}\text { Já comprou algum produto ou alguma marca que viu com o Youtuber que mais } \\
\text { gosta? }\end{array}$ & $45 \%$ & 73 & $48 \%$ & 79 & $7 \%$ & 11 & 163 \\
\hline $\begin{array}{l}\text { Usa ou usou algum produto ou alguma marca que viu com o Youtuber que mais } \\
\text { gosta? }\end{array}$ & $51 \%$ & 83 & $41 \%$ & 67 & $8 \%$ & 13 & 163 \\
\hline Já reproduziu algo que viu em vídeos do(s) seu(s) Youtuber (s) favorito (s)? & $64 \%$ & 103 & $23 \%$ & 38 & $13 \%$ & 21 & 162 \\
\hline Já discordou de alguma atitude do (s) Youtuber (s) favorito (s)? & $66 \%$ & 105 & $20 \%$ & 32 & $14 \%$ & 22 & 159 \\
\hline Você se identifica com o(s) Youtuber (s) que segue? & $50 \%$ & 80 & $17 \%$ & 27 & $34 \%$ & 54 & 161 \\
\hline $\begin{array}{l}\text { Você pesquisa a opinião do (s) seu (s) Youtuber (s) favorito (s) sobre assuntos } \\
\text { que tem dúvida? }\end{array}$ & $22 \%$ & 35 & $48 \%$ & 78 & $30 \%$ & 49 & 162 \\
\hline Você segue o (s) seu (s) Youtuber (s) favorito (s) em outras redes sociais? & $80 \%$ & 129 & $12 \%$ & 20 & $7 \%$ & 12 & 161 \\
\hline
\end{tabular}


Questionados sobre a vontade de se tornar um Youtuber, 51\% (N=83) dos estudantes afirmaram que sim. A Youtuber Luiza Gomes, que possui 324 mil inscritos em seu canal, em entrevista para a presente pesquisa, afirmou que um Youtuber tem influência sobre seus seguidores:

"Acaba sendo inevitável, quanto mais identificação você cria com o público mais relevante para ele você se torna! Os seguidores acabam acompanhado quando influenciador cria uma empatia e tem um estilo de vida parecido ou que pessoa almeja".

Para o gamer Cabralzada, também participante da entrevista, que vincula a comunicação com seus inscritos entre diversas redes sociais considera que a admiração é a palavra-chave:

\footnotetext{
“As pessoas gostam de ver o que eles se projetam ser na lá na frente. Muitas vezes a falta de recursos ou oportunidade independem que eles chegam; de onde vem a admiração deles por quem consegue chegar lá".
}

A pesquisa revelou ainda que $47 \%(\mathrm{~N}=80)$ dos estudantes respondentes falam gírias e expressões que seus Youtubers utilizam, 51\% $(\mathrm{N}=83)$ usa ou usou algum produto ou marca indicadas pelos Youtubers, $64 \%(\mathrm{~N}=103)$ já reproduziu algo que viu nos vídeos, $50 \%(\mathrm{~N}=80)$ se identificam com os Youtubers que seguem. Esses dados revelam certo nível de influência em relação ao sonho de se transformarem em Youtubers, no modo de falar e agir, na utilização de objetos como roupas e livros semelhantes aos influenciadores.

Sobre a influência que exerce em seus seguidores quanto ao uso de produtos e serviços indicados por ela e que fazem parte do seu conteúdo, Luiza Gomes afirma que:

"Todo mundo influencia alguém de alguma maneira, sendo influenciador ou não! Eu vivo falando de produtos, dicas e serviços então acabo influenciando muito e tento ter muito cuidado com o que eu falo e faço!”.

Sobre essa afirmativa da entrevistada, a pesquisa mostra que:

- 22\% $(\mathrm{N}=35)$ pesquisam a opinião dos influenciadores sobre assuntos que tem dúvida;

- 66\% $(\mathrm{N}=105)$ dos respondentes afirmam já terem discordado de alguma atitude do seu YouTube favorito.

- $80 \%(\mathrm{~N}=129)$ dos estudantes afirmam que seguem os Youtubers em outras redes sociais;

- 45\% (N=73) quando questionados se compram produtos indicados pelos criadores de conteúdo.

Nota-se, portanto, que os estudantes dos anos finais do Ensino Fundamental, participantes da pesquisa, gostam da plataforma de vídeos e seguem diversos canais, são influenciados em pontos como o modo de falar e agir, porém possuem criticidade para avaliar as atitudes dos Youtubers, discordando quando necessário, assim como indicam ter independência quando a questão envolve compras e indicações dos mesmos.

Dando prosseguimento ao estudo, questionou-se os participantes sobre os critérios que chamam atenção e motivam sua inscrição em canais do Youtube. Os estudantes afirmaram ser a diversão e originalidade como as características mais importantes/motivadoras. (Figura 5) 


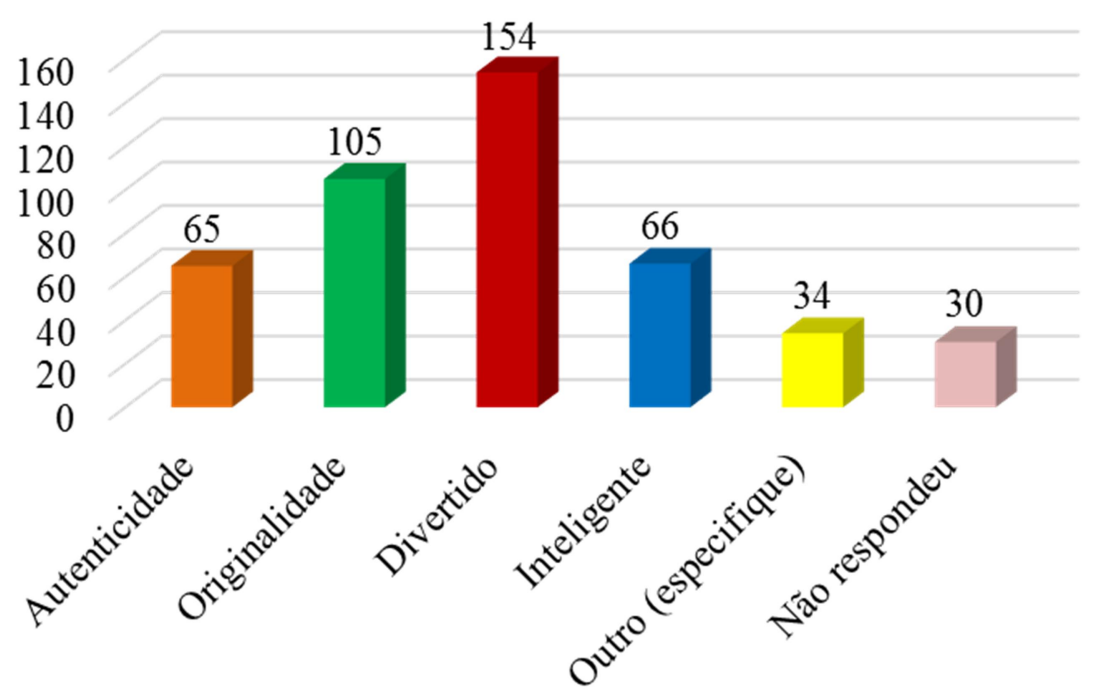

Figura 5: Critérios para inscrição nos canais.

Fonte: Elaboração própria / Pesquisa de campo.

Os adolescentes procuram canais com que se identificam e, como o foco principal na busca do YouTube para os entrevistados é se divertir, a característica "divertido" ficou no topo do resultado, paralelamente onde veem algo que se inspiram, eles se inscrevem seja autenticidade originalidade ou inteligência.

\begin{abstract}
Se pudéssemos desenhar o YouTube como um ecossistema, ele se apoiaria em três pilares: criadores, conteúdo e audiência. Os grandes motores para garantir esse ecossistema vivo são a identificação e a paixão. Ou seja, quando as pessoas assistem a vídeos online, elas querem se reconhecer, encontrar grupos com que se identificam e assistir a toda a pluralidade do mundo (COELHO; CAMPOS, 2019, $\mathrm{s} / \mathrm{p})$.
\end{abstract}

Em entrevista ao "Programa do Porchat" (2016), os Youtubers Lukas e Daniel, donos do canal "Você Sabia", o quarto maior do Brasil em 2020, que contempla curiosidades e fatos históricos, quando questionados pelo apresentador sobre a maneira que a juventude entende ou aprende mais, Lucas afirmou: "A galera quer ver foto, vídeo, imagem, texto... hoje em dia é bem diferente". Mesmo o canal não se intitulando como de estudo, muitos inscritos comentam que os vídeos os ajudaram na escola, sendo assim os Youtubers utilizam ferramentas que encaram como facilitadoras para o entendimento, pois afirmam que seu público é bastante visual.

O termo aprendizagem, pela sua natureza cognitiva e multidisciplinar, não apresenta apenas um único conceito, indica definições diversas "em diferentes áreas do conhecimento, independente da abordagem individual ou organizacional" (KREMER; AKAHOSHI; CAVALHEIRO, 2017, p. 31).

Com uma pergunta direta "Você se sente influenciado pelos Youtubers que segue?", as respostas foram pontuais, 55\% ( $\mathrm{N}=107)$ afirmaram que não se sentem diretamente influenciado pelos Youtubers que acompanha, 28\% (N=54) que sim, se sentem influenciados por eles e $17 \%(\mathrm{~N}=33)$ não responderam essa questão. 
Ressalta quedos 55\% ( $\mathrm{N}=107)$ dos estudantes que afirmaram não serem diretamente influenciados pelos Youtubers, $80 \%$ seguem os Youtubers em outras redes, $49 \%$ reproduzem falas e atitudes, $51 \%$ utilizam objetos e produtos que os mesmos usam e divulgam (Tabela 4).

Segundo Costa e Miranda (2019) os Youtubers, tornam-se eles próprios os fenômenos, na medida em que não é a mídia que interfere no comportamento social, mas as celebridades, influenciando seja no jeito de falar, na postura, nos gostos e, inclusive, nas pretensões profissionais de crianças e jovens. A internet transformou de forma profunda a sociedade e as relações humanas. O compartilhamento de dados, imagens e conteúdos gerou um ambiente que tem influenciado cultural e socialmente a coletividade. O YouTube, transformou-se em palco e holofote para novas celebridades, exercendo um grande poder sobre as gerações mais jovens. Os fenômenos culturais desenvolveram sentimentos de vínculo coletivo.

Para youtber Luiza Gomes, um Youtuber tem influência sobre seus seguidores:

\footnotetext{
“As pessoas gostam de ver o que eles se projetam ser na lá na frente. Muita vezes a falta de recursos ou oportunidade independem que eles chegam; de onde vem a admiração deles por quem consegue chegar lá".
}

Segundo Costa e Miranda (2019) os Youtubers, tornam-se eles próprios os fenômenos, na medida em que não é a mídia que interfere no comportamento social, mas as celebridades, influenciando seja no jeito de falar, na postura, nos gostos e, inclusive, nas pretensões profissionais de crianças e jovens. A internet transformou de forma profunda a sociedade e as relações humanas. O compartilhamento de dados, imagens e conteúdos gerou um ambiente que tem influenciado cultural e socialmente a coletividade. O YouTube, transformou-se em palco para novas celebridades, exercendo um forte poder sobre as gerações mais jovens. Os fenômenos culturais criam sentimentos de vínculo coletivo.

\section{CONSIDERAÇÕES FINAIS}

A pesquisa em questão analisa a influência na relação do estudante dos anos finais do Ensino Fundamental com os Youtubers. Além de compreender se ela ocorre, o como e onde acontece. A população da pesquisa foi de 194 estudantes, distribuídos entre rede particular e pública de ensino, da cidade de Campos dos Goytacazes, no estado do Rio de Janeiro, além de entrevista a dois Youtubers locais.

A aceitação para a participação no questionário e o compartilhamento do mesmo entre os estudantes revelou o interesse que eles possuem sobre a temática principal: plataforma de vídeos Youtube. Os resultados aqui encontrados não fazem parte de um universo total, porém são significativos em função do tamanho da população.

A revisão de literatura indicou o quanto o Youtube mudou a maneira de consumir conteúdo na internet, democratizou a produção de conteúdo audiovisual, dispensando a necessidade de grandes equipamentos e espaços físicos. Surge, inclusive, uma nova profissão, o Youtuber, que com apenas um celular na mão, consegue atingir números milionários de visualizações em seus vídeos, tornando-se celebridades e conhecidos como influenciadores digitais.

Entende-se aqui, o termo "influência" como a mudança de comportamento na presença tanto "real" quanto "imaginária" de outra pessoa. Pode-se perceber após a análise dos dados que os adolescentes estudantes dos anos iniciais do Ensino Fundamental, respondentes, gostam do Youtube, passam mais de três horas por dia na plataforma buscando se divertirem,

Persp. Online: hum \& sociais aplicada., Campos dos Goytacazes, 30 (11)17-37- 2021

seer.perspectivasonline.com.br 
se inscrevem em canais onde encontram originalidade, autencidade e inteligência e são influenciados em alguns pontos.

O estudo crítico do arcabouço teórico possibilitou a constatação de que a plataforma Youtube, no Brasil, ocupa um lugar de destaque entre as redes sociais mais usadas. Compreende-se também a relevância do tema da pesquisa em questão, visto que a plataforma de vídeos faz parte do cotidiano da maioria dos brasileiros.

Durante a pesquisa de campo os adolescentes respondentes não se consideram diretamente influenciados pelos Youtubers favoritos, entretanto o estudo revela que passam horas visualizando vídeos, entretidos com assuntos de seus interesses - humor, música e games, usam gírias, expressões e objetos vistos, além de indicarem canais para os amigos. Destaca-se porém, que não deixam de lado a criticidade para avaliar atitudes tomadas pelos influenciadores, discordando sempre que acham necessário.

\section{REFERÊNCIAS}

AGENCIA MOLL. As 10 redes sociais mais usadas no Brasil em 2020. Disponível em: https://agenciamoll.com.br/redes-sociais-mais-usadas-no-brasil/. Acesso em 02 jun. 2020.

BAUMAN, Z. Zygmunt Bauman: "Vivemos tempos líquidos. Nada é para durar". [Entrevista cedida a] Adriana Prado. Isto é online. 2007. EDIÇÃO No 2636 17/07. Disponível em:https://istoe.com.br/102755_VIVEMOS+TEMPOS+LIQUIDOS+NADA+E+DURAR+/. Acesso em: 10 out. 2019.

BARCELOS, G. T. (2014). REDES SOCIAIS E FORMAÇÃO DE PROFESSORES. Perspectivas Online: Humanas \& Sociais Aplicadas, 2(5). Disponível em: https://ojs3.perspectivasonline.com.br/humanas_sociais_e_aplicadas/article/view/62/41. Acesso em: 20 jan. 2021.

BERNARDAZZI, R.; COSTA, M. H. B. V. Produtores de conteúdo no YouTube e as relações com a produção audiovisual. Communicare, São Paulo, v. 17, p. 146-160, 2017. Disponível em: https://casperlibero.edu.br/wp-content/uploads /2017/09/Artigo-7Communicare-17-Edi\%C3\%A7\%C3\%A3o-Especial.pdf. Acesso em: 20 abr. 2020.

BRASIL. Base Nacional Comum Curricular: documento completo. Brasília: MEC/Secretaria de Educação Básica, 2018. Disponível em: http://basenacionalcomum.mec.gov.br/images/BNCC_EI_EF_110518_versaofinal_site.pdf. Acesso em: 11 nov. 2019.

BURGESS, J.; GREEN, J. YouTube e a revolução digital: como o maior fenômeno da cultura participativa transformou a mídia e a sociedade. São Paulo: Aleph, 2009.

COELHO, F.; CAMPOS, M. YouTube: único para todo mundo. 2019. Disponível em: https://www.thinkwithgoogle.com/intl/pt-br/advertising-channels/v\%C3\%AD deo/youtubeunico-para-todo-mundo/. Acesso em: 10 jun. 2020.

CORTELAZZO, Â. Metodologias ativas e personalizadas de aprendizagem: para refinar seu cardápio. Rio de Janeiro: Alta Books, 2018. 
COSTA, E.; MIRANDA, R. Seleção Brasileira ou Youtuber. Revista Alterjor, v. 20, n. 2, p. 42-62, 14 jul. 2019. Disponível em: https://www.revistas.usp.br/ alterjor/article/view/157739/154454. Acesso em: 20 jun. 2020.

COSTA, T. Quais são as redes sociais mais usadas no Brasil em 2019? Disponível em:https://rockcontent.com/blog/redes-sociais-mais-usadas-no-brasil/. Acesso em: 17 set. 2019.

DIAS, R. C. Resenha: modernidade e identidade. Psicologia \& Sociedade, v. 17, n. 3, p. 8788, 2005. Disponível em: http://www.scielo.br/scielo.php?Script= sci_arttext\&pid=S0102$71822005000300013 \& \operatorname{lng}=$ en\&nrm=iso. Acesso em: 29 set. 2019.

FAGUNDES, M.M. Competência informacional e geração z: um estudo de caso em duas escolas de Porto Alegre. 2011. 105f. Monografia (Bacharelado em Biblioteconomia). Universidade Federal do Rio Grande do Sul. 2011. Disponível em: https://www.lume.ufrgs.br/handle/10183/37536. Acesso em: 28 nov. 2019.

GIL, A. C. Como elaborar projetas de pesquisai. 4. ed. São Paulo: Atlas, 2002.

JENKINS, H. Cultura da convergência. Tradução por Suzana Alexandria. São Paulo: Editora Aleph, 2013. Disponível em: https://www.nucleodepesquisado sexvotos.org/uploads/4/4/8/9/4489229/cultura_da_convergencia_-_henry _ jenkins.pdf. Acesso em: 20 mar. 2020

KIUCHI, C.; SILVA, J. O.; GOMES, L. R. R. Youtubers: a nova geração de influenciadores. Revista Científica UMC, v. 3, n. 1, 2018. Disponível em: http://seer.umc.br/index.php/revistaumc/article/view/214/191. Acesso em: 28 out. 2019.

KREMER, A.M.; AKAHOSHI, W.B.; CAVALHEIRO, R.T. A. Comunidade de prática sob a ótica da análise de redes sociais: uma aplicação em uma cooperativa brasileira. Perpectivas Online: Humanas \& Sociais Aplicadas, v.7, n.20, p.28-42 , 2017. Disponível em

https://ojs3.perspectivasonline.com.br/humanas_sociais_e_aplicadas/article/view/1187/947

Acesso em: 20 jan. 2021.

MAURER, A. L. As gerações $Y$ e $Z$ e suas âncoras de carreira: contribuição para a gestão estratégica de operações. 2013, 122f. Dissertação (Mestrado Profissional em Administração). Universidade de Santa Cruz do Sul - UNISC, Santa Cruz do Sul. 2013. Disponível em: https://repositorio.unisc.br/jspui/bitstream/11624/554/1/AndreMaurer.pdf. Acesso em: 18 set. 2019.

MICHEL, M. H. Metodologia e pesquisa científica em ciências sociais. 2. ed. São Paulo: Atlas, 2009.

MOSCARDI et al. A influência dos youtubers na vida dos adolescentes. Anais do EVINCI UniBrasil. 2017. v. 3 n. 1 (2017): Caderno de Resumos - parte 2. Disponível em: https://portaldeperiodicos.unibrasil.com.br/index.php/anaisevinci /article/view/3664/2948. Acesso em 15 jun. 2020.

NASH, M. A indústria dos games respondeu bem à pandemia. 2020. Disponível em: https://www.thinkwithgoogle.com/intl/pt-br/tendencias-de-consumo /a-industria-dos-games-

Persp. Online: hum \& sociais aplicada., Campos dos Goytacazes, 30 (11)17-37- 2021

seer.perspectivasonline.com.br 
respondeu-bem-a-pandemia-veja-3-ensinamentos-que-podem-impactar-o-seu-marketing/. Acesso em: 14 jul. 2020.

PRENSKY, M. Nativos digitais, imigrantes digitais. 2001. Disponível em:http://poetadasmoreninhas.pbworks.com/w/file/fetch/60222961/Prensky\%20\%20Imigrantes\%20e\%20nativos\%20digitais.pdf. Acesso em: 18 set. 2019.

SAMMUR, J. T.; SILVA, P. E. A. L.; CORTEZ, P. A. Profissão Youtuber: uma revisão crítica sobre os impactos do ciberespaço nas definições de profissão e trabalho em comunicação social. Anais Intercom - Sociedade Brasileira de Estudos Interdisciplinares da Comunicação XX Congresso de Ciências da Comunicação na Região Nordeste-Juazeiro-BA. 2018 Disponível: https://portalintercom.org.br/ anais/nordeste2018/resumos/R62-0019-1.pdf. Acesso em: 28 out. 2019.

SOUSA, B. C. de et al.. A influência dos youtubers na personalidade do adolescente: aprendizagem observacional. In: Anais da Mostra de Pesquisa em Ciência e Tecnologia 2017. Anais...Fortaleza (CE) DeVry Brasil - Damásio - Ibmec, 2019. Disponível em: https//www.even3.com.br/anais/mpct2017/47446-A-INFLUENCIA-DOS-YOUTUBERSNA-PERSONALIDADE-DO-ADOLESCENTE--APRENDIZAGEM-OBSERVACIONAL. Acesso em: 15 jun. 2020.

TEIXEIRA, H. O que é Influência Social? 2015. Disponível em: http://www.helioteixeira.org/psicologia-social/o-que-e-influencia-social/.Acesso em: 30 nov. 2019. 